\title{
RESIDUAL LIFE OF SPINOSAD ON KIWIFRUIT - BIOLOGICAL AND CHEMICAL STUDIES
}

\author{
A.R. TOMKINS, P.T. HOLLAND, C. THOMSON, \\ D.J. WILSON and C.P. MALCOLM
HortResearch, Ruakura Research Centre, Private Bag 3123, Hamilton, New Zealand

\begin{abstract}
Residual life of the insecticide spinosad (Success Naturalyte), on kiwifruit cv. Hayward foliage, was determined by bioassay and chemical techniques. Spinosad was applied at 1.2 - $19.2 \mathrm{~g} / 100$ litres. Leaves were sampled for analysis at intervals between 1 and 55 days post-application. Neonate brownheaded leafroller (Ctenopseustis obliquana) larvae were exposed to residues for 1, 4 or 7 days. Spinosad had persistent residual activity on kiwifruit foliage, with $2.4 \mathrm{~g} / 100$ litres or more, giving $98 \%$ control for up to 28 days after application. The proportion of spinosynA to -D on the treated leaves was initially 4:1 and decreased with time due to the greater persistence of spinosyn-D. The residue declines for spinosyn-A and-D over days 1 to 28 fitted first order models. Half-lives were 6.2-12 and 10-16.5 days for spinosyn-A and -D respectively with faster degradation at the lower rates.
\end{abstract}

Keywords: Spinosad, kiwifruit, residues, foliage, Ctenopseustis obliquana.

\section{INTRODUCTION}

Spinosad is a naturally-derived insecticide which is produced by fermentation of the bacterium, Saccharopolyspora spinosa. It consists of a mixture of related spinosyn toxins, principally spinosyn-A and -D. It has contact and stomach poison activity against insects belonging to Coleoptera, Diptera, Hymenoptera, Isoptera, Lepidoptera, Siphonoptera and Thysanoptera but little or no activity against sucking insects, predatory insects (Elzen et al. 1998) and mites (Anon 1997). Treated insects are affected quite rapidly, but may remain alive for up to two days without feeding. Spinosad has been used overseas on a range of crop, ornamental, forestry, greenhouse, garden and household plants (Anon. 1997).

Spinosyn-A and -D have similar structures and properties, both being nonvolatile, relatively non-polar natural products which adsorb to soils and sediments. Their major degradation pathway is photolysis, with half-lives of a few days reported on soil and plant surfaces (Anon. 1997).

As spinosad appears to have low toxicity to many beneficial insects (Elzen et al. 1998), it has potential for use in Integrated Pest Management (IPM) systems. Currently, leafroller control under KiwiGreen, the kiwifruit IPM system, depends primarily on insecticides based on the bacterium Bacillus thuringiensis $(\mathrm{Bt})$. Whilst a few well-timed sprays of Bt provide effective leafroller control, the introduction of insecticides from other classes would help reduce the potential for resistance development.

This paper reports studies conducted with Spinosad on kiwifruit, which form part of a larger project developing a model for predicting insecticide residue decay and activity as a tool to assist spray application timing. 


\section{Field application}

\section{METHODS}

Treatments were applied to mature kiwifruit vines cv. Hayward in an unsprayed Waikato orchard. Four replicates were used per treatment, each consisting of 20 tagged leaves, with unsprayed vines as buffers between treatment vines. Treatments were applied to run off on 21 November 1997 using a handheld sprayer. Spinosad (as Success Naturalyte (NAF-313), $120 \mathrm{~g} /$ litre) was applied at 1.2, 2.4, 4.8, 9.6 and 19.2 $\mathrm{g} / 100$ litres.

\section{Residue sampling}

Two leaf discs per sprayed leaf, each $20 \mathrm{~mm}$ in diameter, were taken with a leaf punch on 1, 3, 7, 14, 21, 28 and 55 days after spraying. One leaf disc was used for bioassaying with brownheaded leafroller (BHLR) larvae (Ctenopseustis obliquana) and the other was retained for residue analysis. Over the duration of the trial, air temperatures ranged from 5 to $27^{\circ} \mathrm{C}$ and there was 7 to $12 \mathrm{~mm}$ of rain per day on 7 days. Bioassay studies

Each bioassay leaf disc was individually caged with a neonate BHLR larva. After 1, 3 and 7 days exposure to the leaf discs, each larva was microscopically examined and assessed as live, dead or moribund.

\section{Residue analysis}

The leaf discs were bulked for each replicate and placed in light-proof glass jars. Residues were extracted by adding $20 \mathrm{ml}$ of hexane and then gently shaking each jar for 30 minutes, before storage at $4^{\circ} \mathrm{C}$ until analysis. An aliquot of the extract was blown dry and re-dissolved in 1:1 acetonitrile/water. Residues of spinosyn-A and -D were then determined simultaneously by reversed-phase high-performance liquid chromatography (RP-HPLC) with ultraviolet detection at $250 \mathrm{~nm}$. The instrument was calibrated with a range of concentrations of a spinosad standard run under the same chromatographic conditions. The proportions of spinosyn-A and -D in the technical spinosad standard were calculated from their respective peak areas, assuming equal UV extinction coefficients.

\section{Biossay studies}

\section{RESULTS AND DISCUSSION}

Spinosad had very persistent residual activity against neonate BHLR larvae. This is shown by the high level of mortality still occurring 28 days after application, even with the lowest rate of spinosad used in this trial (1.2 g/100 litres) (Fig. 1). Mortality continued to increase when larvae were exposed to residues for up to 7 days. Control mortality was less than $5 \%$ at all exposure times on untreated leaf discs.

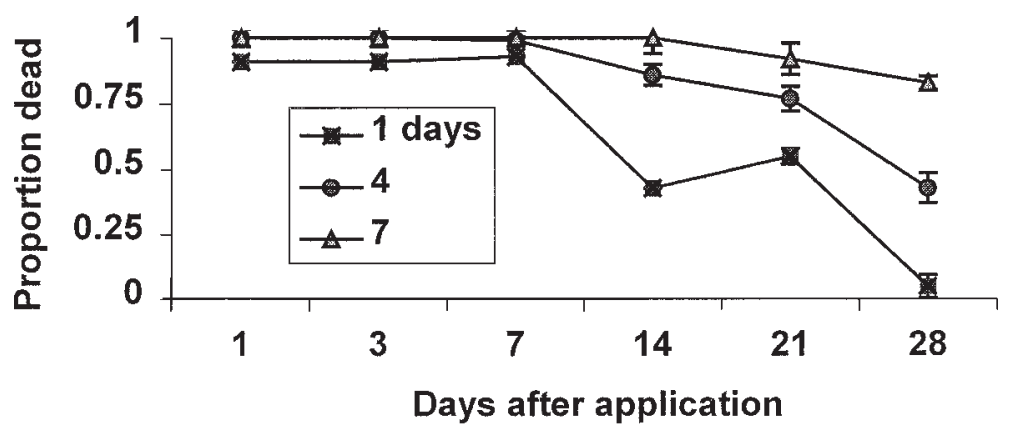

FIGURE 1: Proportion ( \pm se) of neonate Ctenopseustis obliquana larvae dead after 1, 4 or 7 days exposure to various aged residues of spinosad after an application of $1.2 \mathrm{~g} / \mathbf{1 0 0}$ litres to kiwifruit foliage. 


\section{Residue analysis}

The RP-HPLC analysis gave distinct peaks for spinosyns A and D, with no significant interferences from leaf co-extractives. The concentrations of spinosyns on the leaf samples were expressed on a projected area basis. The detection limit was 8 $\mathrm{ng} / \mathrm{cm}^{2}$. Recoveries of spinosad spiked onto leaf discs and immediately extracted were $89 \pm 5 \%$ at the equivalent of $150 \mathrm{ng} / \mathrm{cm}^{2}$. This relatively direct and sensitive method is considerably less complex than that reported for determining spinosad residues on vegetable crops (Yeh et al. 1997).

The decline in residues for both spinosyns closely fitted a first order model over the first 28 days (Fig. 2, Table $1, \mathrm{r}^{2}=0.96-0.99$ ). The proportions of spinosyn-A and -D in the spinosad formulation used in this trial were approximately $4: 1$. However, spinosyn-D was significantly more persistent on kiwifruit leaves with half lives consistently $30-40 \%$ longer than for spinosyn-A at the various treatment rates (Table 1). The half-lives for both spinosyns were not constant with rate, with lower persistence at the lower application rates. The residues from the lower rate treatments (1.2 and $2.4 \mathrm{~g} / 100$ litres) became non-detectable after 7-14 days. There was an indication that the residues from the higher rate treatments remaining after 28 days were more persistent than in the initial period (Fig. 2).

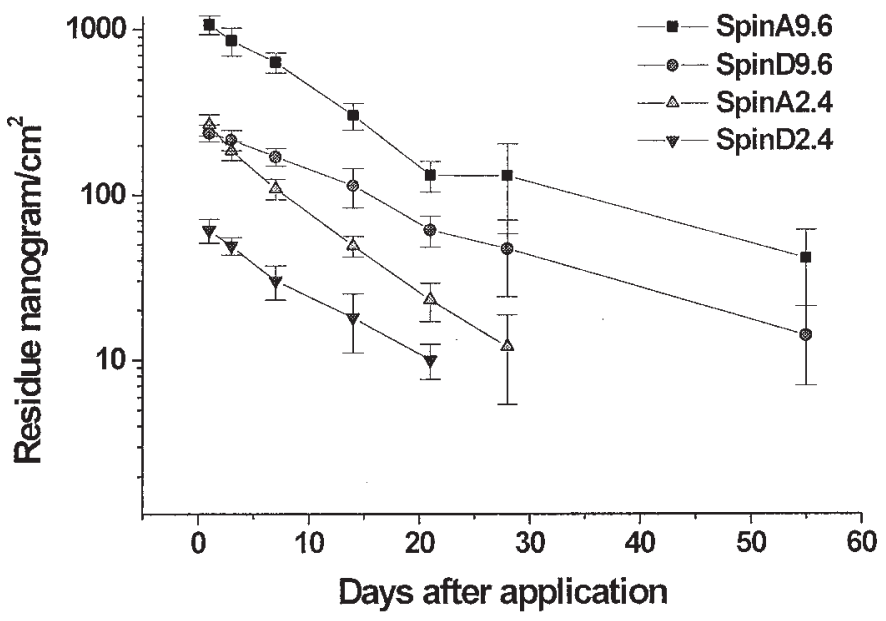

FIGURE 2: Decay of spinosyn-A and $-D$ residues $\left(\mathrm{ng} / \mathrm{cm}^{2} \pm \mathrm{se}\right)$ on kiwifruit leaves following applications of spinosad at 2.4 and $9.6 \mathrm{~g} / 100$ litres.

TABLE 1: First order intercepts (day 0) and half lives (days) for decay of spinosyn residues on kiwifruit foliage.

\begin{tabular}{ccccc}
\hline \multirow{2}{*}{$\begin{array}{c}\text { Rate } \\
\text { (g/100 litres) }\end{array}$} & \multicolumn{2}{c}{ Spinosyn-A } & \multicolumn{2}{c}{ Spinosyn-D } \\
& $\begin{array}{c}\text { Intercept } \\
\left.\text { (day 0, ng/cm }{ }^{2}\right)\end{array}$ & $\begin{array}{c}\text { Half-life } \\
\text { (days) }\end{array}$ & $\begin{array}{c}\text { Intercept } \\
\left.\text { (day 0, ng/cm }{ }^{2}\right)\end{array}$ & $\begin{array}{c}\text { Half-life } \\
\text { (days) }\end{array}$ \\
\hline 1.2 & 130 & 6.2 & 30 & 10.0 \\
2.4 & 260 & 6.1 & 65 & 7.8 \\
4.8 & 640 & 8.0 & 150 & 10.4 \\
9.6 & 1080 & 8.2 & 260 & 11.0 \\
19.2 & 1480 & 12.0 & 375 & 16.5 \\
\hline
\end{tabular}


The relationship between the level of spinosyn residue and insect mortality was described by the following formula and fitted by regression analysis:

Proportion of insects dead $=1 /\left(1+\mathrm{e}^{-(\mathrm{a}+\mathrm{bx})}\right)$, where $\mathrm{x}=\log _{10}($ spinosyn residue +0.01$)$

The intercept (a) and slope (b) for the total spinosyn residue $(A+D)$ remaining on the leaves at the various times after treatment (all rates) and the proportion of insects dead after 1 or 4 days exposure, were 4.5 and 3.2 and 7.2 and 3.95 respectively. It was assumed that both spinosyns were responsible for causing insect mortality. The activity of spinosad on leaves against BHLR extended below the detection limit of 8 $\mathrm{ng} / \mathrm{cm}^{2}$ for each spinosyn.

Previously, it has been observed that many pesticides are significantly more persistent on kiwifruit than on other fruit crops (Holland et al. 1984). This also appears to apply to spinosyns with half-lives of 10-20 days found on kiwifruit foliage compared to the several days reported on the surfaces of other plant species (McDonald et al. 1998). The corresponding duration of residual activity is also considerably longer than has been reported with spinosad for other insect species on different crops. ie. 7 days for beet armyworm (Spodoptera exigua) on cotton (McDonald et al. 1998).

\section{CONCLUSIONS}

Spinosad had very high activity against neonate BHLR larvae and the activity on treated leaves persisted for long periods. There was a strong relationship between the biological activity of treated leaves and the levels of the spinsosyn-A and -D residues extracted from the leaves. The sensitive and relatively direct method of analysis developed for spinosad residues on leaf material will enable further studies on dose/ persistence/biological activity relationships for this promising new insecticide.

\section{ACKNOWLEDGEMENTS}

Thanks to Dow Elanco for providing a technical sample of spinosad, Dr D. Lauren for assistance with HPLC parameters, Ms T.M. Burnett for technical assistance and Ms. B. Dow for statistical analysis. This project was funded by FRST Contract CO6616.

\section{REFERENCES}

Anonymous, 1997. Spinosad technical document. DowElanco.

Elzen, G.W., Elzen, P.J. and King, E.G., 1998. Laboratory toxicity of insecticide residues to Orius insidiosus, Geocoris punctipes, Hippodamia convergens and Chrysoperla carnea. Southwestern Entomologist 23: 335-342.

Holland, P.T., McGhie, T.K. and C.P. Malcolm., 1984. Residual life of pesticides on kiwifruit. Proc. $37^{\text {th }}$ N.Z. Weed and Pest Cont. Conf.: 136-141.

McDonald, P.T., Kish, M.K., King, P.A., Dunagan, F.J. and Weiland, R.T., 1998. Field persistence of several insecticides on cotton foliage as determined by beet armyworm. (Spodoptera exigua) bioassay. Proceedings Beltwide Cotton Conferences Vol. 2: 1164-1166.

Yeh, L.T., Schwelder, D.A., Schelle, G.E. and Balcer, J.L., 1997. Application of Empore disk extraction for trace analysis of spinosad and metabolites in leafy vegetables, peppers, and tomatoes by high-performance liquid chromatography with ultraviolet detection. J. Agric. Food Chem. 45: 1746-1751. 